\title{
Artificial Stone in France (1830-1930): A Material between Modernity and Tradition
}

\author{
Angelo Bertolazzi \\ Department of Civil, Environmental and Architectural Engineering, University of Padova, Padova 35131, Italy
}

\begin{abstract}
: 1920s and 1930s architecture has often been associated with the use of modern materials, such as reinforced concrete, glass and steel, mainly thanks to the role given them by the historiography of the modern, of presenting a break with former tradition and of spreading the need of architectural renewal. The study of architecture from the point of view of construction techniques evidences, instead, how architectural renewal started earlier, during the 19 century and involved the whole realm of building, even tradition-associated materials, such as wood and stone. Indeed, artificial stone (which appeared in early 19 century) represents-above all in France-a link between traditional construction in stone and the newborn reinforced-concrete technique, so as to underline the gradual shift from 19 century construction codes to the new industrial construction techniques, which in the 1920s and 1930s tend to overlap and blend, in this way determining a material continuity of modern and 19 century architecture.
\end{abstract}

Key words: Artificial stone, industrial techniques, history construction, French architecture, 19 century, modern architecture.

\section{Introduction}

The perception of a planning culture linked to the use of reinforced concrete and cement derives from the methodological setup of the early historiography of the modern movement, whose roots are to be found in the revolution caused by materials and by industrial techniques in late 19 and early 20 centuries and in the figurative revolution enacted by cubism [1]. The modernity of the first half of the 20 century has almost invariably been linked to the widespread use of the reinforced-concrete frame, which-according to Colin Rowe-has become the archetype of new architecture and its spatial matrix, representing what columns and vaults were in classical architecture [2]. Out of this, the essentially spatial interpretation of modern architecture was born, above all as regards architecture connected to avant-gardes and to the modern movement, though later on involving the whole history of architecture [3]. If, on the one hand, this viewpoint has doubtlessly been able to explain

Corresponding author: Angelo Bertolazzi, Ph.D., research fields: modern architecture, construction history and building techniques in stone. E-mail: angelo.bertolazz@unipd.it. some stages in the formation of the modern movement and the relationships between figurative arts, architecture and industry, on the other hand, it has barred that bird's eye view that would have allowed to assess the complexity of the constructive approaches characterizing western architecture between 1910 and 1930, where construction traditions underlie both eclectic and "rationalistic" construction, even if often hidden behind the mask of liberty style or the abstract image of the modern. It has often been forgotten that the technological revolution that developed during the 19 century had already tolled the end of classical constructive language, often transforming the grammatical tenets of classicism from trusty guidelines to grudgingly-borne trammels.

The studies carried out in the last two decades by architectonic historiography have begun to reassess the manifold features of architecture in the first half of the 20 century, features that have often presented an alternative to the rationalistic model in the determination of the modern. At a more general level, this constructive approach allows an insight into the inner nature of the concrete form, whose character has since antiquity been defined by means of the materials 
employed and the way they have been worked and blended together.

Artificial stone, which just appeared in early 19 century, represents the link between traditional stone construction and the newborn technique of reinforced concrete and underlines the gradual steps from 19 century constructive tenets towards the new industrial construction techniques, which in the 1920s and 1930s tend to overlap and mix, determining a material continuity between modern and 19 century architecture. In this evolution, a fundamental role has been played by the patents-above all French ones-which appeared starting from the first half of the 19 century and were employed-following a process of technological evolution-up to the late 1930s. The role of artificial stone within western culture witnesses the shift from a stone-construction culture towards the new concrete (which was shortly to become reinforced-concrete) culture.

\section{Origins and Development (1830-1915)}

The origins of artificial stone can be placed at the dawn of industrialization, i.e., in the first decade of the 19 century, when those technical transformations that were shortly to change the cultural guidelines of architectural practice were being realized. Artificial stone, first used in 18 England, was resorted to, with the addition of marble powder and lime, in the ambit of decorative and scenographic settings in First Empire France, both owing to its being quickly set in place and to its low cost, with regard to the temporary character of the works. In the following decades, new techniques were developed as the result of the growing demand for "serially-produced" decorative elements and the first patents started to appear. Among these, the Lenseur patent (8.05.1838) can be mentioned, required for a "pierre cèrame meant as a substitute for natural limestone, a material complying with stone-cutting regulations” [4]. Artificial stone, at first given different names according to its composition and use, (pierre cèrame, pierre artificielle, marbre factice, marbre fondu and pierre marbriére), then started being resorted to as a substitute for natural stone, thanks to its capability to be easily carved and set in place, which dramatically cut costs. Demands of English and French patents for this kind of material increased rapidly and as the number of such stones grew, so did their brand names, causing a mighty mess as far as their composition and suitability for particular uses were concerned. This applies above all to the common name of pierre factice, which—at least at the beginning — denotes both "stones" manufactured out of baked clay and of ground natural stone or marble. In 1887, in order to stop such mess, they started to resort to the process of production of the stones, the moulage (grinding) Fig. 1 as the criterion of classification, hence the term pierre moulée [5].

If, on the one hand, architects were the first to appreciate the capabilities as decorative elements offered by the new materials, during the first half of the 19 century engineers began to discover the technical capabilities of artificial stone. One of the first who realized the mechanical properties of pierre factice was M. Fleuret in 1807, he maintained that "well-made pierre factice soon acquires the hardness

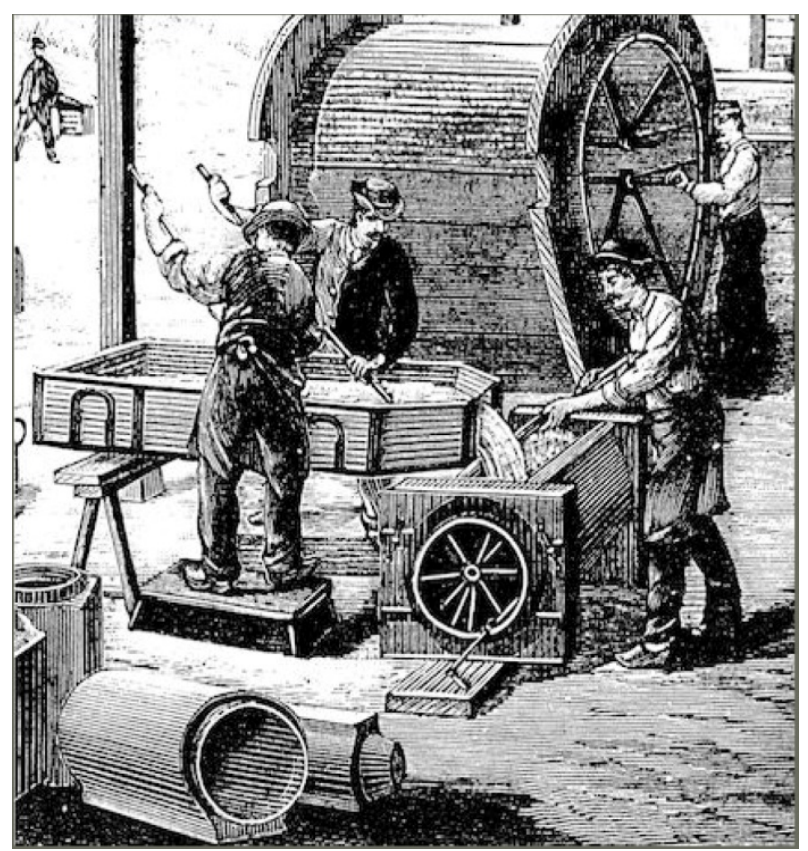

Fig. 1 Moulage of pierre factice, engraving, 1860. 
of natural stones, even the hardest ones and is not subject to gelivity. Besides, by means of molds, it can take any shape one may wish. Thanks to colored and polished plasters, it can be made to look like marble with its stains, streaks and shades" [6]. This artificial material could easily overcome the drawbacks posed by natural stone as far as gelivity and endurance to wear and tear were concerned, besides it was cheaper and its performance could be tested by checking the components of the blend and how it matured, even on samples. The pierre factice was therefore newly resorted to in civil engineering, for example hydraulic works, quays and piers [7].

In 1845, a French patent was issued (29.04.1845) about Randsome artificial stone (22.10.1844 English patent), a blend of concrete, sand and chips of stone that was ground and mixed with water so as to obtain a flowing mixture, which was then allowed to dry inside frames or purpose-built molds. The mixture was obtained as follows: "first melt $50 \mathrm{~kg}$ of sodium carbonate in $100 \mathrm{~L}$ of water, then melt $25 \mathrm{~kg}$ of potassium carbonate again in $100 \mathrm{~L}$ of water, adding a certain amount of lime. Let the mixture boil so as to reduce it to $40 \mathrm{~L}$. Add $50 \mathrm{~kg}$ of limestone powder and heat for $12 \mathrm{~h}$ in an iron barrel at a pressure of $30 \mathrm{~kg}$ per $37 \mathrm{~mm}^{2}$. You will obtain a concrete powder that can be used mixed with water and sand [8]. The resistance of the "stone" obtained depended on the size of the grains of powder used. Later on, this patent was to be added an extension purporting "the improvement of an artificial stone and the methods to make it less subject to wear and tear" [9].

In 1843 Jean-Auguste Lebrun entered his demand of patent for an artificial stone, he named pierre hydroplastique. As many as nine extensions were added to this patent, granted on 13.11.1844, purporting further improvements of the mixture and the grinding. Lebrun's pierre factice was presented at the 1855 Paris Universal Exhibition, where it obtained sizable acknowledgements thanks to its pleasant aspect and hardness, on a par-if not better-when compared with the best natural stones. In the 13th February 1854 report, written by the architects and engineers commission appointed by the Haute-Garonne Préfet, it is in fact stated that "Labrun's stone is not subject to shrinking and has undergone several tests, such as different weather conditions, crushing, wear and tear caused by friction and gelivity tests, etc.. Not only have comparative tests proved the superior quality of Lebrun's products to the best bricks, but, even more, their worth, on a par with Carbados and Beaucaire stones for cutting” [10]. Its strong point was therefore being cheaper than natural stone for cutting, allowing up to $65 \%-75 \%$, savings, according to Lebrun [10]. This material met with a certain success, it can in fact still be found in early 20 century manuals [11], even abroad. For example, in Daniele Donghi's Manuale dell' Architetto, the composition of Lebrun's artificial stone is reported: "five parts of stones producing either hydraulic lime or concrete and one of coke coal is ground together into very fine powder. Bricks are made out of this powder, which are baked in ordinary kilns and then ground again into a powder named hydro. This powder is mixed with sand at a 1:3 ratio, and then the paste-like mixture is pressed into purpose-built molds, etc.. These stones resist crushing at a rate of $81 \mathrm{~kg} / \mathrm{cm}^{2}$, they withstand severe weather conditions fairly well: they do not shrink and are not gelive" [11].

Universal exhibitions had a primary role in the commercial success of artificial stones, even furthering later improvements and the achievement of new solutions, on such occasions not only were new patents exhibited, but also artificial-stone temporary set-ups often presented (Fig. 2), public tests were carried out in order to prove the validity of such material. However, as already stated, there is an underlying ambiguity in choosing this material: on the one hand, regarded as an inferior-quality substitute for natural-stone blocks when building; on the other, as providing elements of ready-made decoration capable 


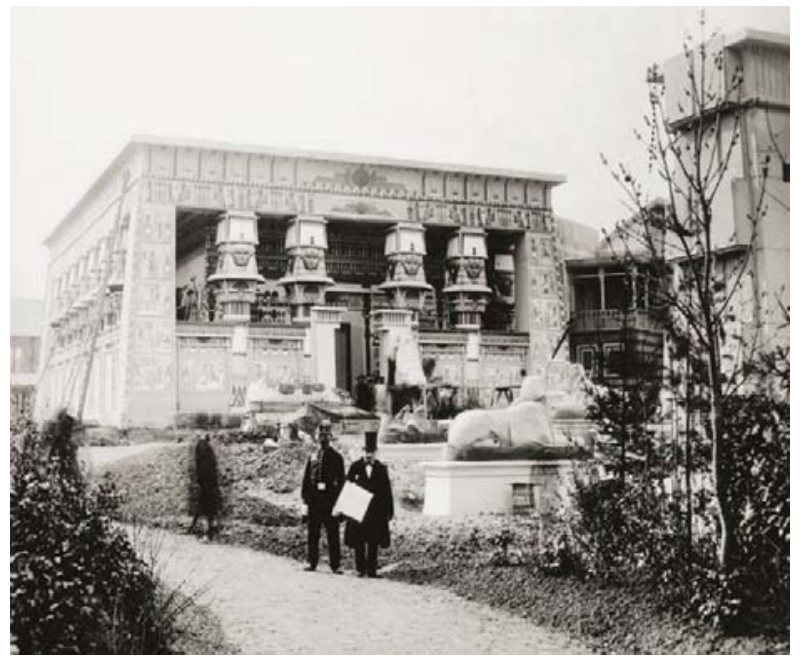

Fig. 2 The "Egyptian" pavilion, built with artificial stone blocks, at the Universal Exhibition in Paris, 1867.

of substituting hand-carved ones, coming from marble or chalk. This is exemplified in the 1867 Paris exhibition. artificial stones or pierres fabriquées are exhibited in the artificial materials section, together with concrete, stucco and bitumen-produced materials, so that, side by side with Portland concrete, which was widely accepted and used throughout Europe and North America and Coignet's béton agglomerée, there are artificial stones, such as Randsome stone or the Lippmann-Schneckemburger's patented simil-pierre or simil-marbre [12].

This material had been shown in a preview at the 1862 London exhibition, even if demands for patents had already been entered in France (1859) and Belgium (1860). The product was presented in Paris in 1867 with various improvements, so that it might have substituted both stone and marble. Its composition "varies according to the ways it is meant to be employed, as regards either grain, colors or veins. It is produced with concrete, lime and powders of various marbles, mixed with sand and ground bricks to which vegetal fibers, such as hemp and stubble are added. This mixture, after a certain amount of sulphureted water and oil are added, is beaten and pounded, so as to turn the vegetal fibers into paste. It is then poured into molds and takes more or less time to solidify, according to the chemical agents added, e.g., potassium sulphate” [13]. Its physical features and mechanical properties are underlined, evidencing how this material reaches a versatility making it fit for various uses: "The material is compact and light but tough, it is not subject to shrinking while setting, so as to be able to reproduce all the minutest details of the mold with great accuracy. It can, however, be carved like stone and polished like marble, etc.. Such materials are lighter than stone and marble, even if their resistance to crushing is comparable to the best stones in the Paris area, while their price is about half natural stones, and in any case lower than marble [13]". This material is therefore presented as competitive if compared with natural stones, as regards mechanical performance, but above all considering costs, both meant as the price of the material and the versatility in the use of the different elements obtained from the same mixture. They can be molded into the most different shapes, into large-sized elements, obtaining the final shapes quickly, without resorting to further work [13].

During the 19 century in France, as far as the use of artificial stone is concerned, traditional masonry techniques and the new industrial materials slowly start coming together. For example, the habit of smoothing artificial stone elements once set in place, as was done with natural-stone blocks, was kept. On the other hand, there are deep differences between artificial stone and concrete: Though both can be culturally referred to natural stone, the former is acknowledged as having some esthetic value, whereas concrete-owing to its "functional" nature-is denied any esthetic value and is therefore hidden within the construction. It is meaningful that Francois Coignet, regarded as one of the fathers of reinforced concrete, should have entered two separate patents, one is about artificial stones and one is about concrete monolith constructions, although-regarding the latter-he was searching for ways to improve their esthetic value [14]. To see the esthetic qualities of concrete used in outside structures acknowledged, the authors will have 


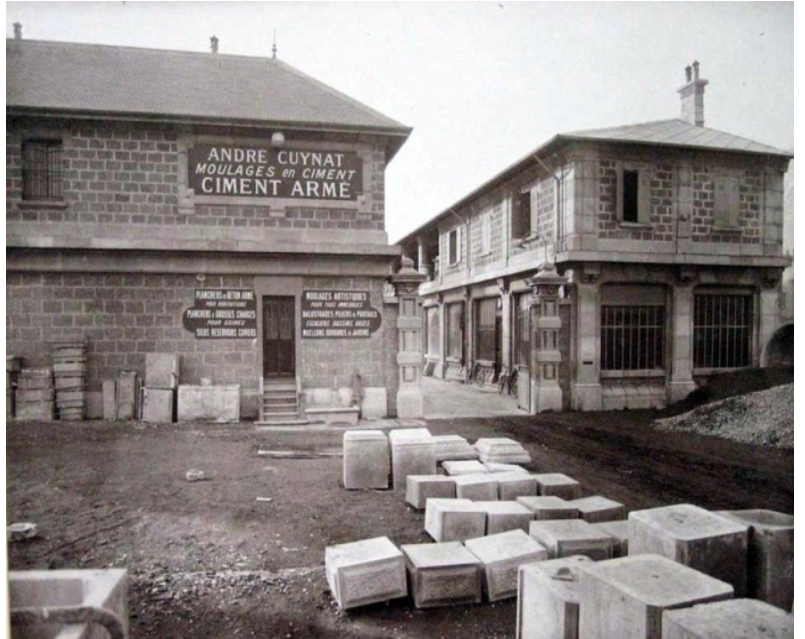

Fig. 3 Blocks of pierre factice at the Usines Cuynat in Grenoble, 1900.

to wait for Auguste Perret's work, he regarded concrete as an esthetically-satisfying substitute for natural stone: "My concrete is finer than stone, I carve and engrave it. Using crushed granite or Vosgi sandstone as inert matter,etc.. I create a material more beautiful than the finest cladding, etc.. Concrete is a stone being born, natural stone is a stone going to die" [15].

What ended up characterizing artificial stone as construction material, not only for decorative elements — as it was the case with baked clay_-was the addition to its ground-stone mixture of Portland concrete, invented by Joseph Aspidin in 1824, Portland started being used in 1840 to confer better resistance to the material, in 1860 Chatelier set down its correct chemical composition, so that it could be easily industrialized and rapidly used, thanks to a more and more varied and diversified offer, as testified by the growing number of new patents suggesting new compounds and the growing demand for added extensions, rendering such patents up-to-date until early 20 century (Fig. 3).

In Donghi's manual, which well describes the transition from traditional construction methods to new industrial technologies, further kinds of artificial stone can be found, deriving from English and French patents, such as Randsome artificial stone, Victoria stone, the already-quoted Lebrun stone, Barteau stone and Wilson artificial stone. They were often modified, for example, Coignet's concrete mix for artificial stones were modified by Manfredini to be specifically used in foundations and continuous brickwork.

Artificial stone has therefore a double role, side by side with reinforced concrete, either of decoration or of protection. Both "functions" get to be fully expressed in cladding, which, at the very end of the 19 century, starts being widely resorted to, both as rational and inexpensive construction principle and as theoretical principle. Cladding meant as protection is evidenced by Perret himself in his $25^{\text {bis }}$ (Immeuble $25^{\text {bis }}$ Rue Franklin), Rue Franklin home (1903): Here he expressed his doubts on the resistance of reinforced concrete to severe weather conditions, that is why he chose a kind of cladding - in this case ceramic_-able both to underline and at the same time protect the reinforced-concrete framework [16].

The widespread resort to artificial stone in France-above all in Paris_-is moreover to be linked to the growing demand for construction materials characterizing the second half of the 19 century, when after the exploitation of the underground quarries in town was forbidden on grounds of law and order (1813) — the quarries of Buttes Chaumont (1860) and Montmatre (1870) were dramatically dwindling. That's why new materials (e.g., artificial stones) and new construction techniques (cladding), in order to substitute or cut costs on natural stones and marble, were resorted to Ref. [17].

\section{Decline and Duration in Modern Architecture (1915-1940)}

Artificial stones, subject to wide experimenting and large use up to World War One, dwindled in importance in the 1920s and 1930s. First of all, the campaign led by the modern movement in favor of modern materials and above all of the truthfulness that was to underlie their use, caused the role played by cladding in determining modernity to be forgotten [18], but even slighted the contribution of artificial stone as "modern" and "rational” material. In fact, if cladding has always had the role of masking [19], of 
hiding the true nature of the building, artificial-stone cladding meant masking twice over: as cladding itself and as dissembling natural stone. Another factor that caused artificial stone to lose its importance has been the growing industrialization of natural-stone quarrying, since resorting to diamond-studded wires (1880-1895) and multiple-blade cutting frames (1827-1925) allowed both the rationalization of cutting in the quarry and the realization of thinner and cheaper slabs, which led to the 1930s thin-stone cladding.

Artificial stone cladding has, however, met with some success in France between the wars: regarded as a cheap material, which-in connection with structural framework-was able to convey to new buildings the dignity of real stone, so linking industrial modernity to traditional stone-construction. In the 1920s there are still several new patents, above all from the United Kingdom and the USA, regarding instruments, productive cycles and composition of various artificial stones. These years saw in fact the conclusion of the industrialization process of artificial stone, thanks to ways devised to refine the mixtures, which became more and more complex, to obtain thinner and more resistant elements. At the same time even new pre-fabricated solutions are tested: They entail placing natural-stone or artificial-stone slabs on top of concrete elements to provide cladding, as well as insulation of the walls [20] (Fig. 4).

In France, even foreign-made products start being used, such as "hollow building blocks" [21], hollow artificial-stone blocks patented in USA that could be assembled to create monolithic brickwork anchored to concrete floors. The hollow spaces increase heat and noise insulation and allow the setup of cables and plumbing. The addition of ground natural stone and white concrete lent a more pleasing look to the elements.

Even the molds were transformed to create new, more regular and thinner, with smoother fronts elements [22]

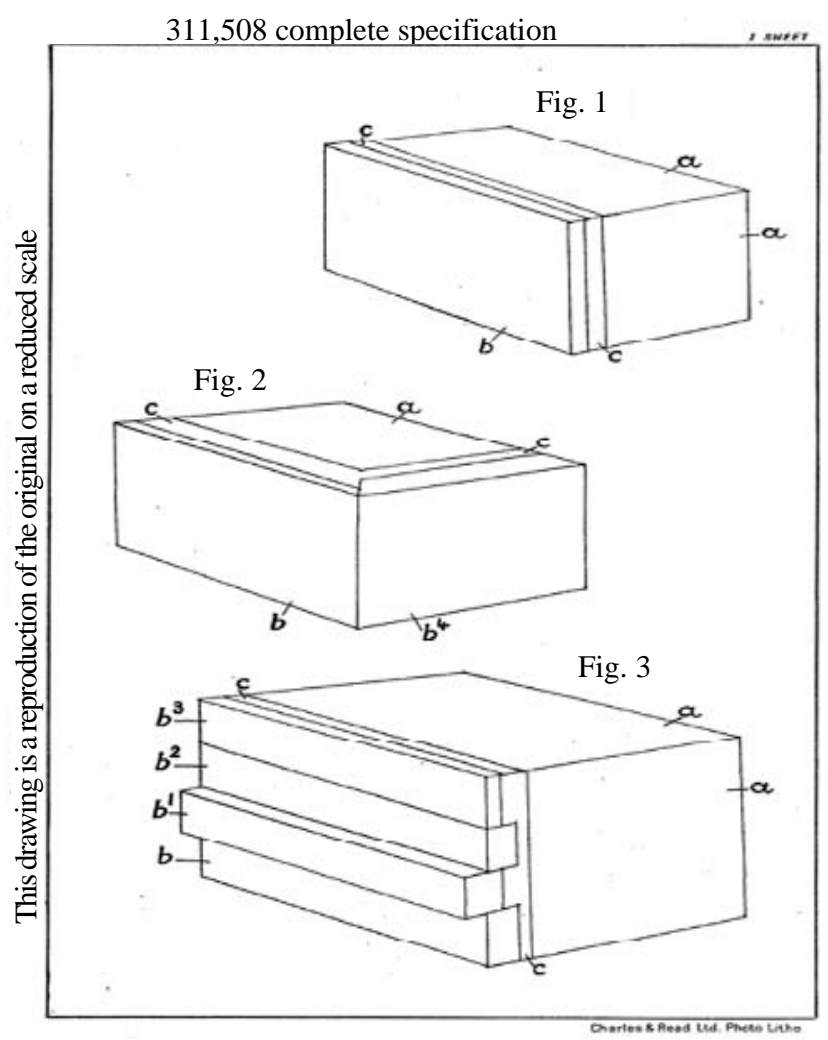

Fig. 4 British patent N 311580/16.05.1929 “the manufacture of concrete building blocks faced with natural stone”. 


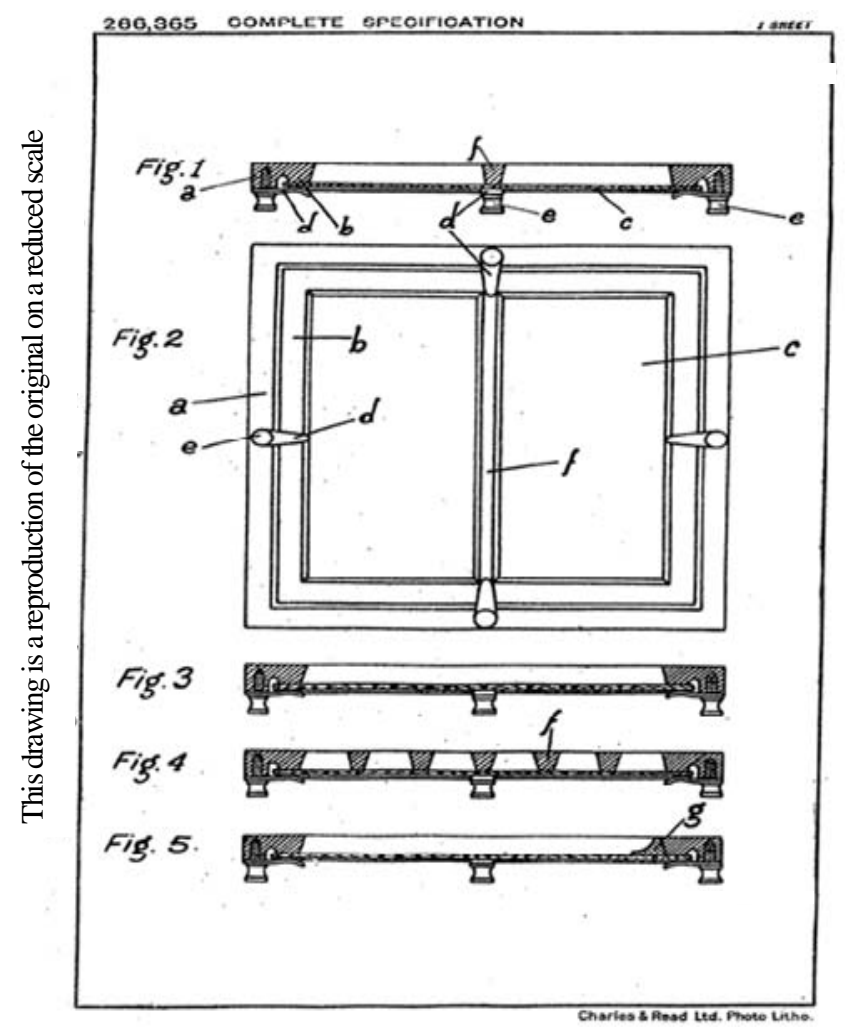

Fig. 5 British patent N 266365/15.09.1927, a mould for the manufacture of an artificial stone.

(Fig. 5), so as to withstand weather conditions with more resistant surfaces, beside complying with the new stylistic trends of the modern movement. This evidences once more how patents have played a basic role in shaping the new "international" construction culture, based on the industrial materials that characterized modern architectural languages.

In France, therefore, artificial stone was being constantly used, often side by side with new industrial materials, mainly with a view to building rapidly and cheaply, though preserving certain monumental features. This is exemplified by Montparnasse-Maine Station (Fig. 6), built between 1927 and 1929 by architect Henry Pacon. The plan meant enlarging Montparnasse Station, which was required by the increase in passengers and goods traffic. The Railways Central Managing Board intended it to be a temporary building, so that the need to do the work rapidly and cheaply led to technologically—innovative solutions, resorting to materials other than steel and glass, which might somehow have been more suitable for a temporary building.

The now-demolished station consisted in a prefabricated and wide reinforced-concrete framework (especially in the larger rooms), whereas the outside walls consisted in concrete brickwork with very large inert material and pierre moulée cladding, presenting peculiar features: The slabs were molded into pre-set shapes, with catches at their backs, so as to do away with metal staples, their fronts bore the moldings and lines the design of the facade required. This procedure allowed the different elements to be manufactured directly at the base of the building, as the brickwork was rising. The thinner and very long elements were instead reinforced with steel-rod frames, according to the pierre armée Pauchot technique. The procedure was a hybrid between reinforced concrete and artificial stone. Commercialized by Société anonyme des constructions en fer-béton et pierres armée fréres Pauchot, between 1904 and 1932, it met with a certain success, first in building fake neo-Gothic ruins, then 
applied to particular construction solutions, for example wide-sized openings (Fig. 7).

The system used in Gare Maine-Montparnasse was patented (Nasoutsky patent) both as regards artificial-stone composition and the laying of the elements (Fig. 8).

Instead of sand, the mixture contained finely-ground stone, in this instance Comblanchien stone for the elements of the skirting board and Euville stone for the other elements. The patent determined "100 kg of white concrete, $170 \mathrm{~kg}$ of Portland concrete, $30 \mathrm{~kg}$ of lime, $1.2 \mathrm{~m}^{3}$ of ground stone and $180 \mathrm{~L}$ of water. The amounts of the various components depended on the stone used. The rather

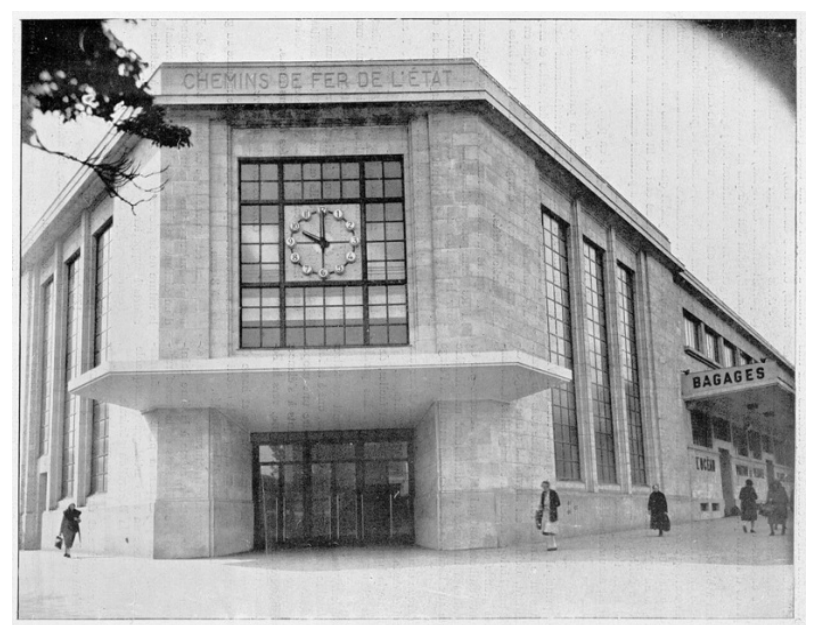

Fig. 6 Montparnasse-Maine Station, 1927-1929 (H, Pacon), from “La Construction Moderne”, Oct. 5, 1930.

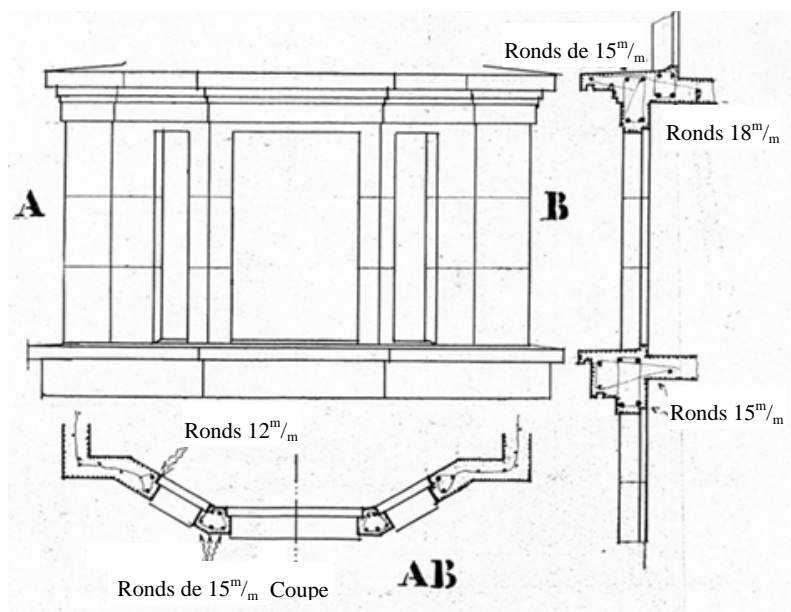

Fig. 1 Pirre armee Pauchot

Fig. 7 Reinforced stone, Patent Pauchot, from "La Construction Moderne“, Oct. 5, 1930.

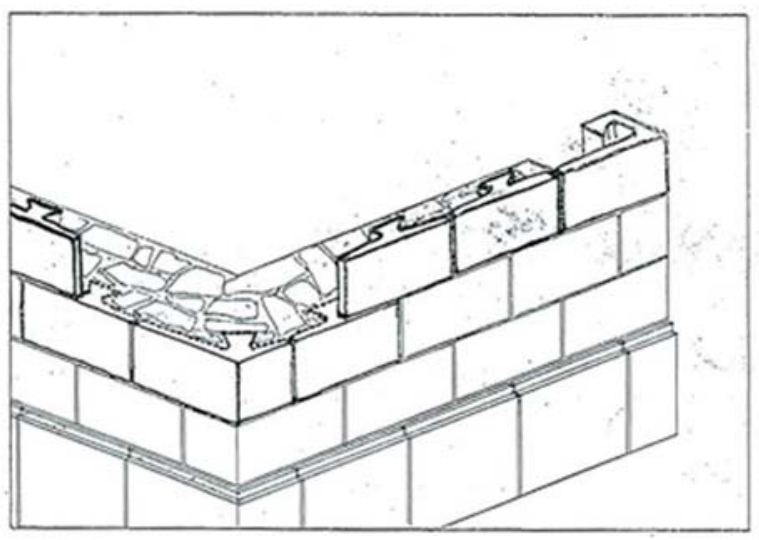

Gare Montparaasse Maine-Revetements

Fig. 8 Montparnasse-maine station, 1927-1929 (Arch, H, Pacon), Patent Nasoutsky, from "La Construction Moderne”, Oct. 5, 1930.

flowing mixture was thoroughly stirred, poured into metal molds, pneumatically vibrated and then allowed to dry three days. Once turned out of their molds, the elements were allowed to season twenty days and finally placed, since after 18 days they had already reached a $200 \mathrm{~kg} / \mathrm{cm}^{2}$ resistance to crushing. Cladding was to proceed simultaneously with the underlying brickwork. Once the wall was raised, the joints were filled and smoothed with the same mixture" [23]. As regards Gare Maine-Montparnasse, the slabs had the following dimensions: $0.65 \mathrm{~m} \times 0.40 \mathrm{~m} \times 0.07 \mathrm{~m}$ in the facing, $1.33 \mathrm{~m} \times 0.52 \mathrm{~m} \times 0.17 \mathrm{~m}$ in the skirting board and $1.33 \mathrm{~m} \times 0.52 \mathrm{~m} \times 0.17 \mathrm{~m}$ in the crowning.

Artificial stone, however, met with a fair success in France in the 1930s, just because it was cheap and rapidly set in place. Beside the above-quoted example of Gare Maine-Montparnasse, it can also be found in other buildings, such as Jean Ginsberg's immeuble de rapport in Rue de Pature. Here the language is closer to Le Corbusier's "five points of the new architecture": ribbon-like-set windows dot an open facade, fitting a free plan. Outside cladding, however, consists in thin slabs of pierre recomposée, another term for artificial stone, secured to the underlying wall by means of six metal staples. They scan and design the facade, conveying a look half-way between Le Corbusier's Modernism and the classical tradition of Paris 
immeuble de rapport.

Between 1935 and 1939 the review L'Architecture d'Aujourd'hui publishes the cahiers techniques, a sort of modern construction-manual, which reveals the complexity and variety of those years' materials and construction techniques. Both the new techniques of construction and of new materials, beside the traditional ones, deriving from 19 century manuals, can be found there. In the issue of dealing with "Revêtements", in the section: materials for plasters and surface finishing, simili-pierrres and marbres artificiels can be found again (Fig. 9). About the former can be read: "when an aggregate amounting to up to 3 at $10 \%$ is used, pleasant-to-the-eye results

\section{AGGLOMÉRÉS DE MARBRE}

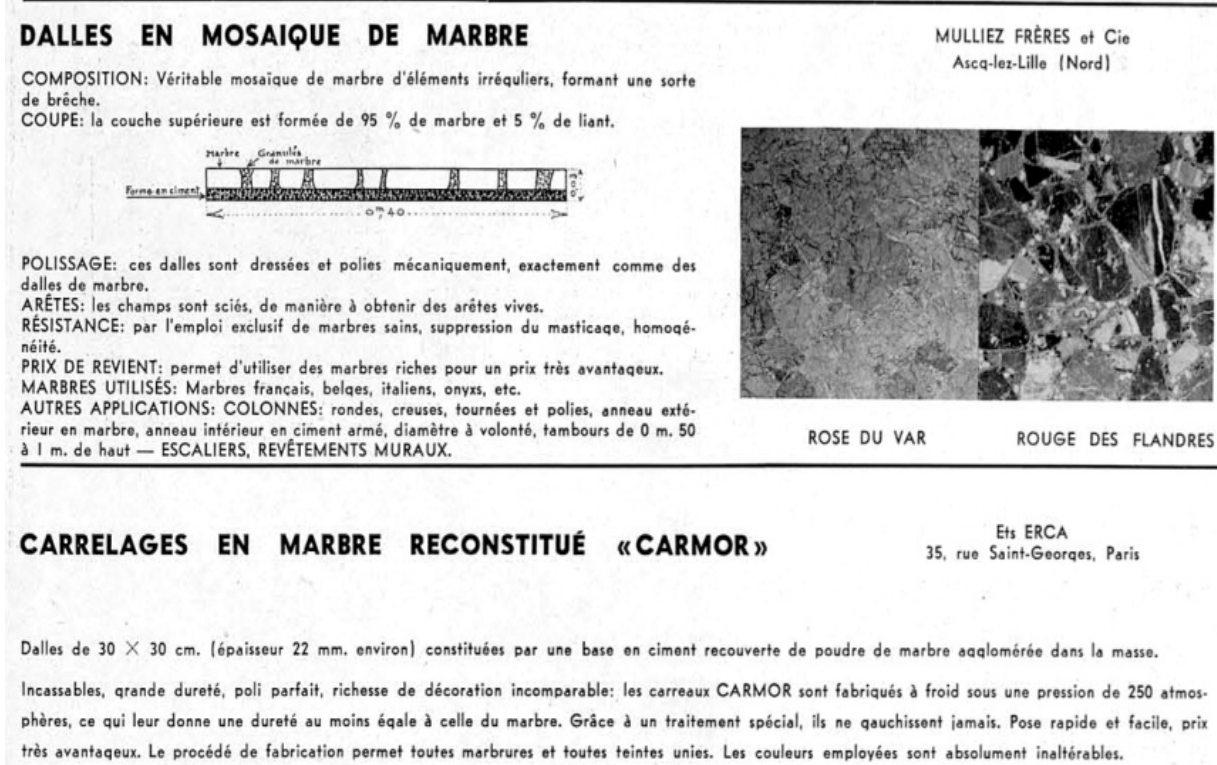

Fig. 9 Advertising for the marbres artificiels, “Cahiers Techniques de l’Architecture d'Aujourd'hui” Dec. 1935.
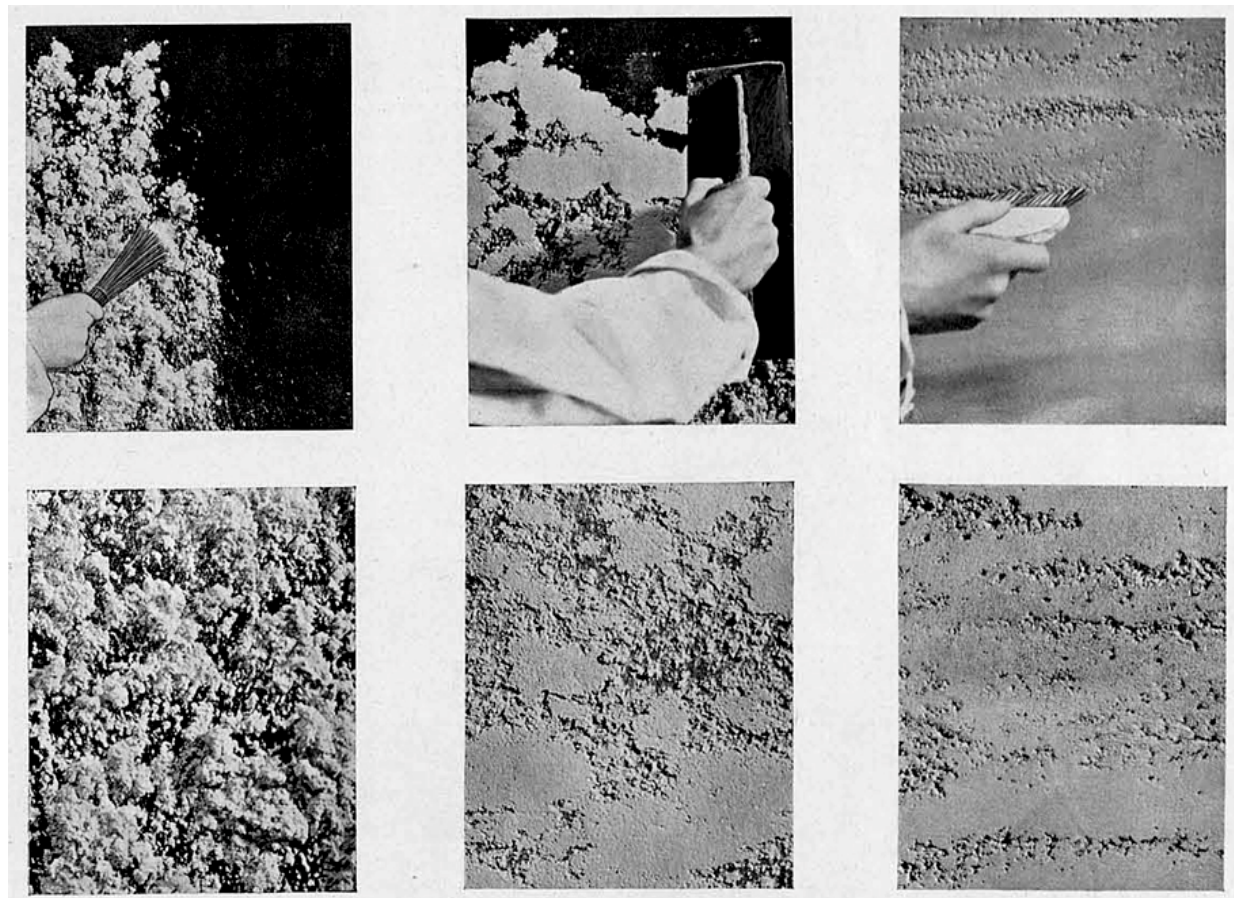

Fig. 10 Revêtements, “Cahiers Techniques de l’Architecture d’Aujourd’hui”, Dec. 1935. 
may be obtained by means of washing, or pounding with blunt-spiked mallets or polishing. When colored concrete is used as aggregate, an artificial stone identical to natural stone is obtained, such imitation becomes perfect if flakes of mica are added. The agglomerates can be used in pre-molded slabs, set in place later in the same way as natural-stone cladding, or else both as continuous or mixed-in-the-brickwork plaster. Pierres reconstituées used abroad are a mixture of white Portland concrete, pebbles and chipped stones, additives then make the mixture waterproof. They may be used either as molded elements or applied directly onto the brickwork. Such materials are not resistant to freeze and resist brackish conditions better than natural stone. Besides, reinforced elements can be manufactured. Pierres reconstituées for inside use are a mixture of Keene (or similar) concrete and stone chips" [24]. As regards marbre artificiel, instead, it is "preferably applied to the brickwork itself. It is a mixture of Keene (or similar) concrete, died so as to look like the marble it is meant to mimic. This material is profitable when manufacturing monoliths, such as columns, cross-pieces or moldings, etc. and is used to clad reinforced-concrete volumes. When used on flat surfaces, sizable savings in comparison with marble are not evident" [24].

It can be noticed how-if compared with the former century-the composition and some physical properties of the material (resistance to frost) have not been subject to change, whereas other ones have been prompted by this material being newly used as thin cladding (resistance to brackish conditions), completely substituting artificial stones. The latest evolution produced by this material made thinner and thinner, used either as continuous plaster or as pigments in concrete, even if considering marbres artificiels applied onto flat surfaces, no sizable savings can be obtained, as a result, the material is best used to manufacture serial decorations. The imitation of natural materials is made even more credible by resorting to mica chips, so that marine sediments or organic debris may be figured, or through applying metal brushes in order to mimic the uneven texture of travertine (Fig. 10).

The resort to artificial stone, in 1920s and 1930s French architecture has the features of a valid economic system, particularly suitable for reinforced-concrete buildings. The thinning of artificial-stone elements is shared by all the materials used in cladding brickwork (natural stones, bricks, ceramic, metal and industrial materials as a whole) and is in keeping with the process of construction rationalization featuring 1920s and 1930s modern architecture, whose roots are to be traced back to the middle 19 century industrial revolution.

\section{Conclusions}

The process of construction rationalization (meant also in its economic implications) during the 19 century, led to the introduction not only of new construction systems, framework and cladding, which substituted traditional brickwork continuity, but even to the resort to new industrial materials, which sometimes were used together with and sometimes substituted traditional ones. So, in the same way as, regarding structures, iron and its by-products were relied on, since they afforded better control in terms of resistance and economic optimization through calculations, even new materials (such as stone for cutting, with reference to France) were sought, to be used side by side and sometimes substitute traditional ones, taking their lower costs and easier manufacturing and handling into account.

Artificial stone, its development and its use in France between the 19 and 20 centuries, is a meaningful landmark in the evolution from weight-bearing continuous brickwork, to the new frontier opened by reinforced-concrete framework coupled with thin cladding, which affords a mediation between tradition and modernity. 


\section{References}

[1] S. Giedion, Space, Time and Architecture: The Growth of a New Tradition, W.W. Norton \& Company, New York, 1966.

[2] C. Rowe, The Chicago Frame, on the Mathematics of the Ideal Villa and Other Essays, MIT Press, Cambridge, 1976.

[3] B. Zevi, Saper Vedere L'architettura, Einaudi, Torino, 1948.

[4] V. Negre, L’ornement en Série, Architecture, Terre Cuite et Carton-Pierre, Mardaga, Parigi-Liegi, 2006.

[5] L. Moulage, Principales applications, collections et modèles reproduits par plâtre, in: The Conference of the Occasion of 9ème Exposition de l'Union Centrale des Ars Décoratifs, Revue d'Art Décoratifs, 2008, pp. 1887-1888.

[6] M. Fleuret, L’Art de Composer des Pierres Factices Aussi Dures que le Caillou, Pont-à-Mousson, Chez l'Auteur, Paris, 1807, p. 11.

[7] T. Chateau, Matériaux Factices ou Pierres Artificielles Proprement Dites, in Technologie du Bâtiment, Paris, 1863-1866, pp. 289-301.

[8] Le Génie Industriel, Revue des Inventions Françaises et étrangères, t. 3ème, Paris, 1852, p. 39.

[9] J. Randsome, Artificial Stone, Description des machines et procédés, pour lesquels des brevets d'invention ont été pris sous le régime de la loi du 5 juillet 1844, t. 60ème, French patent, 30.03.1857 (1791).

[10] L’Ami des sciences, Année I, n50, Patent 16.12.1855, pp. 496-497.

[11] D. Donghi, Il manuale dell'Architetto, UTET (Unione Tipografico-Editrice Torinese), Torino, 1906-1935, pp. 350-357.
[12] M. Garnier, Artificial marble, Catalogue des brevets d'invention, d'importation et de perfectionnement, délivrés du 1er janvier au 31 décembre 1843, Bouchard-Huzard, French patent 14869 (1843).

[13] Matériaux de construction, in Exposition Universelle 1867, Rapports du jury international, réunis par ordre de S.E. M. de la Forcade la Roquette, Ministre de l'agriculture, du commerce et des travaux publics, Paris, 1868, pp. 50-52.

[14] F. Coignet, Artificial stone, French Patent, 30659 (1857).

[15] R. Gargiani, Auguste Perret (1874-1954), Teoria e Opere, Electa, Milano, 1993, p. 257.

[16] V. Gregotti, Perret, 25 bis rue Franklin, Rassegna, n. 28, Anno VIII, Dicembre, 1986, pp. 10-11.

[17] B. Marrey, Matériaux de Paris: l'étoffe de la Ville de l'antiquité à Nos Jours, Parigramme, Parigi, 2002, pp. 110-112.

[18] G. Fanelli, R. Gargiani, Il Principio del Rivestimento, Prolegomena a una Storia dell'architettura Contemporanea, Laterza, Bari, 1994.

[19] S. Giedion, Bauen in Frankreich, Bauen in Eisen, Bauen in Eisenbeton, La Villette, Parigi, 2000.

[20] S. Fletcher, The manufacture of concrete building blocks faced with natural stone, British Patent, 311580 (1929).

[21] C. Sée, Traité Pratique de Construction Moderne, 2vv., Paris, 1926.

[22] V. Aerni, A mould for the manufacture of an artificial stone, British Patent, 266365 (1927).

[23] C. Sée, Exemple d'un revêtement en pierres moulées: la Gare Montparnasse-Maine a Paris, La Construction Moderne, Oct. 1930.

[24] Cahiers Techniques de l'Architecture d'Aujourd'hui n5, Revêtements, Dec. 1935, p. 27. 